BRTTISH MEDICAL JOCRNAL VOLLME $290 \quad 9$ FEBRUARY 1985

PRACTICE OBSERVED

\section{Reflections on Practice}

\section{Cost effectiveness of general practice}

ROGER JONES

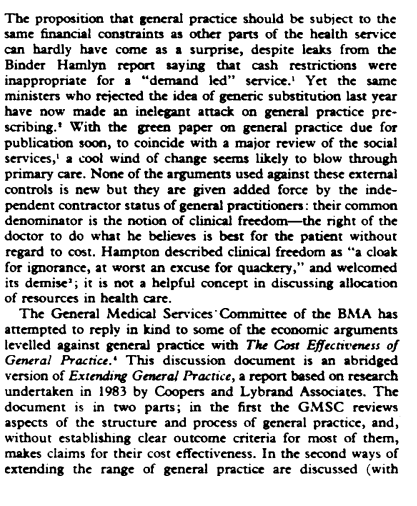

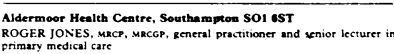

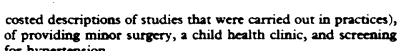

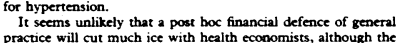
comperative costingses of general prectice with hospitial and local

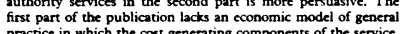

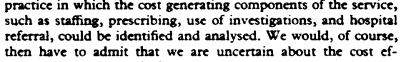

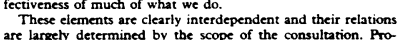

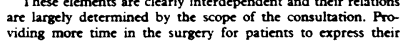

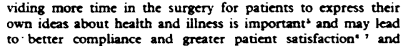

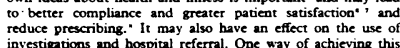

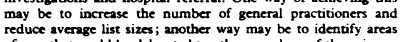

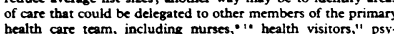

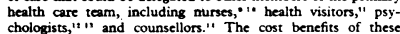

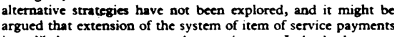
is unlikely $y 0$ encouratec such experiments. Indeded, therer arc

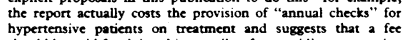
service for by bertension It also contrins the surprising satec

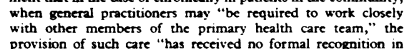

BRITISH MEDICAL JOURNAL VOLUME $290 \quad 9$ FBBRUARY 1985 wects' experience in Denmark and as a patient calling on
Danish doctors for many years. The British experience is of eight months' duration.
Ifind that the British general practicioner works harder than

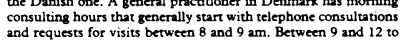
1 o'clock the general practitioner sees patients either with or
without an appointment system. Affer the consulting bours he mayy make onc or two home visisis daily. Thereafifer, , he may have
some paper work such as accounts to take carre of. He will prob-
ably be ready to go home at about 3 pm and will have no more

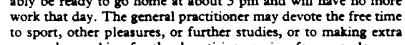
to sport, ocher pleasures, or further studies, or to making extra
money by working for the deputising service, for example.
Most general practioners have four morning consultation

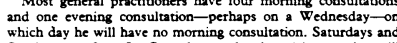
which day he will have no morning consultation. Saturdays and
Sundays are free. In Copenhagen the deputising service will
take care of the emergencies after consultation hours and home

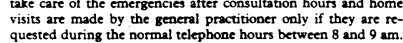
quested during the normal telephone hours between 8 and 9 am.
(Not all general practitioners are that rigid.). Outsside Copenhageen the general pracitioners in one area will share the duties after
consultation hours but may in many cases let young hospited doctors replace them. Young doctors are interested in getring
this extre experience and makning extra money. The doctor who

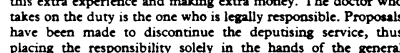
placing the responsibility solely in the hands of the general
practitioners. No step has yet been taken towards such a change. In Denmark it is common for two doctors to share a practice,
but generally the doctors do not form a partmership. Each has

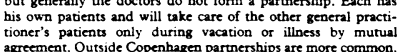

In London the health centre is open from 9 am and staffed
until $630 \mathrm{pm}$. In the morning between 930 and 1130 the patients come without appointments, and in the afternonss from
$430 \mathrm{pm}$ the patients are seren again, this time by appointment$430 \mathrm{pm}$ the patients are seen again, this time by appointment-
except on Thursday afternoons, which are free. Furthermore, in our health centre we have weekly antenatal and family
planning cliniss, and on Saturday morning the centre is open for

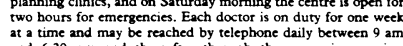
and $630 \mathrm{pm}$ and therefter through the answering service. doctor on call is the one who is legally responsible, and it is he
who offers telephone advice and decides whether to sec the to come to the health centre the following day.
It is much easier for patients to change general practitioner.

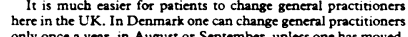

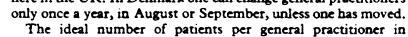
The ideal number of patients per general practitioner in
Denmark
the age of considered to be roughhy 15 are, but children up to to
the counted, and they are estimated to be a fifth to a quarter of the general practitioner's patients. This still
gives a list size of under 1500 compared with 2100 in Britain. gives a list size of under 1500 compared with 2100 in Britain.
Some Danish general practitioners whoh have been long estab-
lished have a larger list size. Prophylactic exaninations on

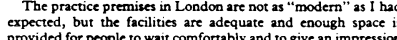
provided for people to wait comforably and ro give an impression
of more cosiness than the generelly more formal Danish sylle,
where in some cases the general practitioner and the nurse mey
W

হ

c

气ิ

D

ํㅡㄹ

言

As certain family planning clinics conists may be firted frece. In Denmark we have a pension for disabled people, which is gran-
ted after due consideration for the rest of the person's life. There

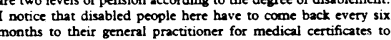
receive their sickness benefit.
In Denmark abortion is avaisble on request but must take

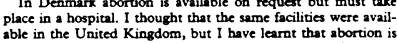
performed on medical or social grounds and requires the signature of two doctors, and thought it secms to be merely a matter of
form, the rules are there. The abortion may take place in nursing In Denmark we have strticter rulues about confirmation of death.
It is not enough to sec that a patient has no heart beat (is dead).

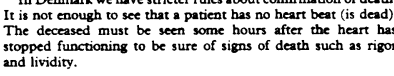

Taking temperature:

One thing that surprised me most-and which sill makes me
wonder - is the different atritude that patients have to taking cempe," and in answer to my question as to how high the tempers. ture is I receive the answer that it has not been taken because the
patient has no thermometer. At first I advised the patients to buy a thermometer and was surprised at the reluctance to such
suggestion uncil I discovered that most of the patients do no a temperature of $39 \cdot 8^{\circ} \mathrm{C}$. . .." In Denmark the temperature is measured in the rectum.
The way some women paticnts dress here is also surprising. Even during the winter some patients with bad coldas of crsycitis
turn up without tights or stockings, with thin nylon underweas and without an overcoat, and look at me in surprise when I advise The British National Formulary makes it fairly casy to write
The of prescriptions when one has become familiar with the booke. Wit
regard to prescriptions, I think that we have a better practice Denmark, as it is compulsory to write on the prescription pre
ciscly how the medicine should be taken and for what reaso
Roman numerals are used for the number of tablets:

$$
\begin{aligned}
& \text { ip tol Nitrazepam No CL. } \\
& \text { ds I trablet at bedtime } \\
& \text { sleeping tablets }
\end{aligned}
$$

It akes longer to write such a prescription, but it is most usefu
for the patients.
130

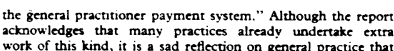
work of this kind, it is a sad reflection on general practice that
che only way to enoourage comprebensive primary care is to
pay general practitioners more for providing it. In private

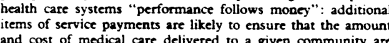
litems of service payments are likely to ensure that the amount
and cost of medical care delivered to a given community are
directly retated to the partern of medical practice not the level of discasc."
How, then, is a profession whose attention has not traditionall focused on the bottom line to establish its conomic credentials
Not, it secms, by comparing itself with ftself nor by aping
hospital models of care. One approach may be to establish

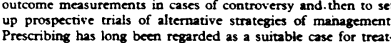
Prescrbing has long been regarded as a suirable case for treat-
ment and the simple outcome measure of prescribing costs
generated by various prescribing policies has already beet used." This is an example of an intermediate outcome because
it excludes end points, such as therapeutic effect, patien studies comparing the length of consultations using prescribisis
soly and referral rates and return visits as intermediate outcomes, or
comparing general prectitioners and practice nurses in the
management of chronic illnosess such as asthma hypertension. and diabetes using indices of control as intermediate outcom and death and complications as definitive outcome measures.
Cost may chen be retated to clinical benefit and rational policy
making becomes possible. The GMSC doeument gives helpful

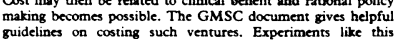

BRITISH MEDTCAL JOURNAL VOLLME $290 \quad 9$ FEBRUARY 1985

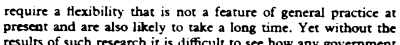
can honestly proceed with crudce cost curting exercrises that may
turm out to have subtle, adverse effects on patient care. Co. tum out to have subtle, adverse effects on patient care. Co
operation between clinicians, economists, and planners is operation between clinicians, economists, and planners is
need pd to provide the information on which to base changes in
the provision of primary care.

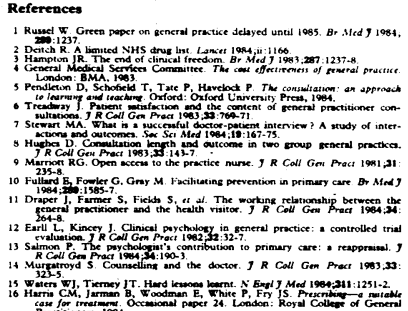

\section{Family Practice}

\section{A Danish view}

INGER HANSSON

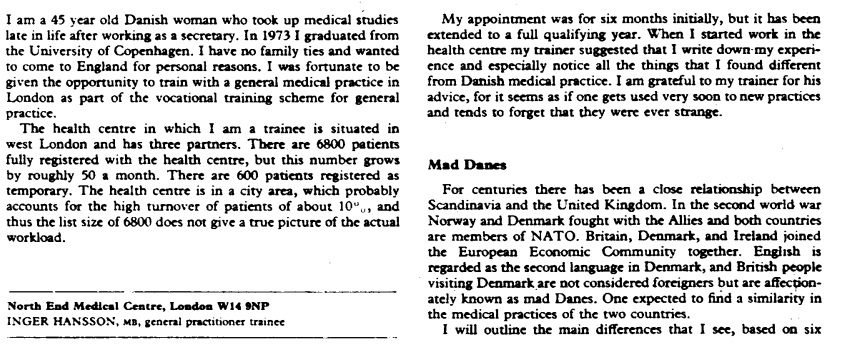

A custom that I find difficult to get used to is the very personal
style of letter writing. In Denmart if we refer a patient to 2

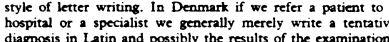
carried out. Here che English language is used instead of Latio
terms, and the letrers are full of personal remarts such as "this pleasant young lady ...., even sometimes going on to describe
which paintings the patient has on his walls. Danish doctors tend to use Letin excessively, veren using ii when speaking to the patient sometrmes, with unfortunate, efiects on the contact
between doctor and patient.
There seems to be a closer relationship with the patients here. It sometimes happens that a doctor will drive a patient to the
hospital, and the general praccitioner will occasionally visit his
patients in the hospital, which is hardly ever done in Denmark patiens in the hospital, which is hardly ever done in Denmark
These are some of the positive espects of British medical practice,
which tend to be reassuring to the parient and win the patient's These are some of the positive aspects of British medical practice
which tend to be reassuring to the patient and win the patient'
confidence. confidence.
Until inow it has been possible for a doctor in Denmark toenter
seneral practice after a period of doing relevant hospital jobs

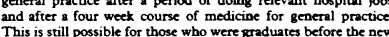
regulations of 1976. For sew graduates wishing to join general
practice six months' training in general practice is compulsor practice six months' training in general practice is compulsory
It is, however, difficult for the young doctors to obtain training posts in general preactioc, as there are few. The salary of the
trainec is paid by the Danish Health System, but the trainer is trainec is paid by the Danish Health System, but the trainer is
not paid to have the traince. No standard training scheme is 2vaiable, and there are no postgraduate examinations such as the
MRCGP (membership of the Royal College of General Pract

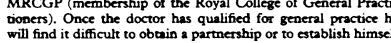

BRTIISH MBDICAL JOURNAL VOLUME $290 \quad 9$ FEBRUNRY 1985 because for some years there has been an overproduction of
doctrors in Denmark. Getting into general proctice is only

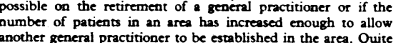
another general practitioner to be sestablished in the area. . Quite
a few Danish doctors are employed abrogd-especially in In the UK postgraduate education seems to be greatly
In empanises, he professionat capatilities of the physycians and
has 2 positive impact on the health care programme of the Conclusion

1 am not sure what my impression will be at the end of my
training. I can say only that the time I have spent so far has o. The informal manner of dealing with patients The experience is fascinating, at times odd and strange, but extremely useful and beneficiall I Im fortunate in having a triner
who has a very good British sense of humour, which makes the task of training a pleasant indulgence.
Last but not least, one of the most important factors that is making my stay benefficial, enioyable, and pleassent is the kind-

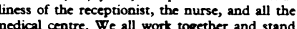
by cach other like a happy family.

Ascopted s December 1989)

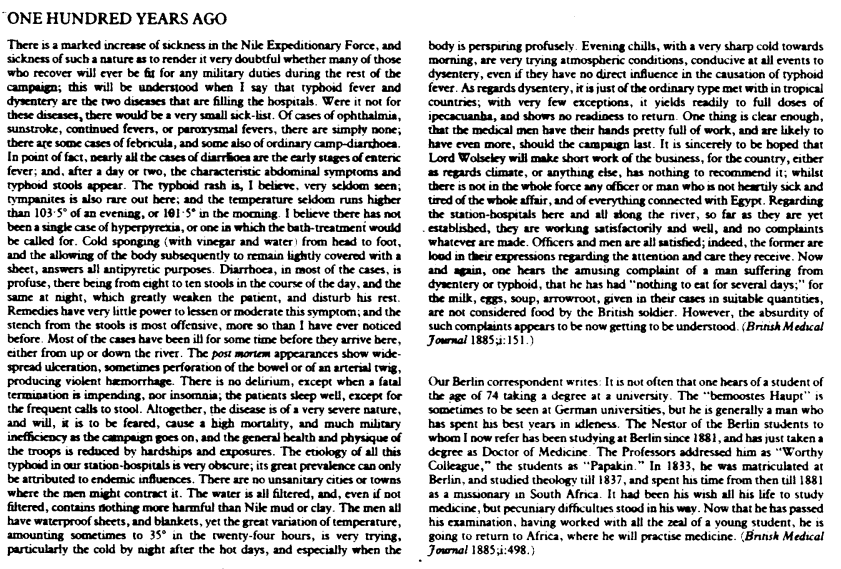

